\title{
Demirci Halı Dokumacılığında Kullanılan Terimler ve Derleme Sözlü̈̆̈̈̈'ndeki Yeri
}

\author{
Prof. Dr. Birsel Oruç Aslan \\ Balıkesir Üniversitesi Necatibey Eğitim Fakültesi \\ Sosyal Bilimler ve Türkçe Eğitimi Bölümü \\ birsel_oruc@hotmail.com
}

\author{
Öğr. Emin Erdem Özbek \\ Millı̂ Ĕ̆itim Bakanlı̆̆ı Dr. Kayabey Ortaokulu \\ erdemozbek@hotmail.com.tr
}

Öz

Bu çalışmada Demirci halı dokumacılığında kullanılan bazı terimler üzerinde durulmuş ve bunların Türk Dil Kurumu tarafından yayınlanmış olan on iki ciltlik Derleme Sözlüğ̈̈'nde yer alıp almadığı araştırılmıştır. Veri toplamada, ilgili çalışmalar da gözden geçirilerek, Demirci'de halı dokuyan kaynak kişilerden yararlanılmıştır. Üç yüz yıllık dokumacılık tarihinde Demirci halıları gündelik kullanımda önemli bir yer tutmaktadır. $\mathrm{Bu}$ durum son yıllarda makine halıcılığının gelişmesiyle gerilemiş̧, Demirci'de halı dokuyanların sayısı azalmaya başlamıştır. Bu sebeple özellikle ilçeye özgü terimlerin en kısa zamanda tespit edilmesi ve halk ağzından derlemeler sözlügüne kazandırılması gerekmektedir. Bu çalışmayla bir nebze de olsa ağız çalışmalarına katkı koymak amaçlanmıştır. Yapılan çalışma sonucunda argaç, arış, kirkit gibi bazı terimlerin Derleme Sözlüğ̈̈nde yer almasına rağmen tespit edilen bölge adlarında Demirci'ye rastlanmaması dikkatimizi çekmiştir. Bazıları da sözlükte başka anlamlarla verilmiştir. Tespit ettiğimiz terimlerden ara urganı, e'lik/eklik, gıyı örneği, iç örneği, ters ilme gibi bazllarının da Derleme Sözlüğü'nde yer almadığı görülmüştür.

Anahtar Kelimeler: Demirci, halı dokumacılığı, Derleme Sözlüğ̈̈, halıcılık terimleri. 


\title{
Terms Used in Demirci Carpet Weaving and Their Position in Derleme Sözlüğ̈̈ (Compilation Dictionary)
}

\begin{abstract}
In this study, some terms used in Demirci carpet weaving are analysed and it is explored whether these words exist in Derleme Sözlü̈̆̈̈ (Compilation Dictionary), a 12-volume publication of Turkish Language Association. In the collection of data, as well as using some related works, we referred to weavers in Demirci as a source. In the two hundred years history of weaving, Demirci carpets have an important place in daily usage. In recent years, this situation is deteriorated with the development in the carpet industry and the number of carpet weavers has decreased. For this reason, it is necessary to identify these region-specific terms as soon as possible and include them in the Derleme Sözlüğü. It is attempted to contribute to dialectology studies by this paper. During our study, it caught our attention that some terms like "argaç, arı̧̧, kirkit" exist in Derleme Sözlü̈̆̈̈, but Demirci is not referred among the regions where these words are used. And some of these are given with different meanings in the dictionary. And also some of the terms we found like ara urgant, e'likleklik, gıyı örneği, iç örneğgi, ters ilme don't exist in the dictionary.
\end{abstract}

Keywords: Demirci, carpet weaving, Derleme Sözlüğ̈̈ (Compilation Dictionary), terms of carpet weaving. 


\section{GíRIŞ}

\section{Türkiye'de Ağız Çalışmaları ve Derleme Sözlüğü}

Ağızlar bir dilin hiç şüphesiz gelişmişliğini, zenginliğini göstermesi açısından önemlidir ve kaybolmadan, teknolojiye yenik düşmeden söz varlığı, söyleyiş özellikleri ve kültür öğeleri ile derlenmelidir.

Anadolu Ağızları üzerine ilk çalışmalar İgnacz Kunos, Kowalski gibi yabancı araştırmacılarca yapılmıştır. Ardından, Anadolu ağızlarının ilk sözlügünü hazırlama çabaları, cumhuriyetin ilk yıllarına, Maarif Vekaleti'nin (Milli Eğitim Bakanlığı) derleme çalışmalarına değin uzanır. Bu çalışmaların ilk ürünü İshak Refet [Işıtman] ve Hamit Zübeyr [Koşay] Beylerin çalışmasıyla Anadilden Derlemeler adı altında 1932 yılında yayımlanmıştır (Ölmez, 2010: 187). 1932 yılında kurulan Türk Dili Tetkik Cemiyeti'nin de ilk kurultayından sonra ele aldığı ilk işlerden biri, halk ağzından derlemeler yapmak olmuştur. Her ilde derleme heyetleri kurulmuş, buna bağlı olarak köylere kadar bir örgütlenme sağlanmış ve 1933 yılında bütün yurtta bir derleme seferberliği başlamıştır. Böylece, yazı dilimize girmemiş, kaynaklarda yer almayan kelimelerin kayıt altına alınması amacıyla, 1932-1960 yılları arasında tüm yurt çapında büyük bir derleme faaliyeti yapılmıştır. Bunun sonucunda 1939-1957 yılları arasında 5 ciltlik "Türkiye'de Halk Ağzından Söz Derleme Dergisi" yayımlanmıştır. 1963-1982 yılları arasında yapılan derleme çalışmaları ile eser 12 cilde tamamlanarak "Türkiye'de Halk Ağzından Derleme Sözlüğü" adı altında yayımlanmıştır. Sözlügüun ikinci baskısı 1993 yılında, birleştirilmiş tıpkıbasım şeklinde olan üçüncü baskısı da 2009 yılında yapılmıştır. Sözlük, 600.000'den fazla fişe dayanan malzemeden oluşan en kapsamlı sözlük olma niteliğini taşımaktadır.

1940'lı yıllarda Türk Dili Tetkik Cemiyetinin başlatmış olduğu derleme seferberliğine Ahmet Caferoğlu da "Anadolu Ağızlarından Toplamalar, Anadolu Diyalektolojisi Üzerine Malzeme I-II" gibi derleme çalışmalarıla katkıda bulunmuştur. Anadolu ağızları yöreden yöreye değişiklik ve benzerlik gösterebildiği için bunların sınıflandırılması da gerekmiş, ilk sınıflandırmaları İ.Kunos ve A.Caferoğlu yapmışlardır (Karahan. 1996: IX ve X). Ağız sinıflandırması konusunda yapılan son ve kapsamlı çalışma olan Anadolu Ağızlarının Sinıflandırılması Prof. Dr. Leyla Karahan'a aittir ve TDK tarafından basılmıştır. Zamanla ağızlar üzerinde yapılan çalışmalar artmış, il il müstakil derlemelerin yer aldığı incelemeler, kitaplar halinde yayımlanmıştır. Kütahya, Ordu, Diyarbakır, Urfa, Gaziantep, Kars, Erzurum, Elazığ, Antalya, Muğla, Trabzon, Adana vs ili ağızları gibi adlarla yayımlanan bu çalışmalarda daha ziyade ses bilgisi ön plana çıkmaktadır. Eserlerde derlenen metinlerin tam bir sözlüğüne de yer verilmemiştir. Ağızlarımızın sözvarlığını araştıran Gülseren Tor'a

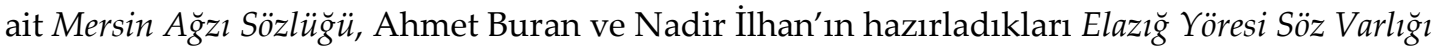
gibi incelemeler ise sözvarlığı alanında başlangıç teşkil eden eserlerdir.

Demirci ilçesinin bağlı bulunduğu Manisa ili üzerinde yapılan ağız çalışmalarından en kapsamlısı ve en yenisi olan Manisa Ağızları adlı eser Prof. Dr. Ayşe İlker tarafından hazırlanmıştır. Eserde diğer ağız araştırmalarında olduğu gibi ses bilgisi ve biçim bilgisi açısından detaylı bir şekilde inceleme yer almaktadır. Eserde Demirci yöresinden derlemeler de yer almakla birlikte halıcılıkla ilgili metne rastlanmamıştır. Buna mukabil Gördes'ten yapılan derlemeler arasında halıcılıkla ilgili metinler bulunmaktadır. Metinlerde āgaç (argaç), āşın (arşın),halı çakısı, kirkit, dīdılanma; güzüle-, kırk-, il-, kāgas (kargas) gibi terimler yöresel söyleyişleriyle geçmektedir. Bu terimlerin dışında halıcılıkla ilgili başka malzemeye pek rastlanmaz. 
Zeynep Korkmaz'ın "Güney-Batı Anadolu Ağızları Ses Bilgisi (Fonetik)" adlı eserinde Manisa ve yöresi ağızları bölümünde Demirci ağzından derleme yapılmadığı görülmektedir.

Manisa ve yöresine ait ağız çalışmaları üniversitelerimizde yüksek lisans ve doktora araştırmalarına da konu olmuştur. Bunlardan Senem Akyol'un hazırladığ 1 "Manisa Merkez Kuzey-Batı Köylerinin Ağız Özellikleri" adlı yüksek lisans tezinde yöreye ait pek çok ağız özelliği tespit edilmekle birlikte Demirci ve halıcllıkla ilgili veriye rastlanmamaktadır.

Ahmet Oyar'ın hazırlamış olduğu Salihli İlçesi ve Köyleri Ağızlarından Derlemeler, adlı yayımlanmamış yüksek lisans tezi ise sadece Salihli ve köylerini ele almaktadır.

Görüldüğü üzere son yıllarda Manisa ve yöresine ait önemli çalışmalar yapılmıştır. Bununla birlikte bu çalışmalar yörenin dil, kültür ve sosyal hayat birikiminin tamamı değildir. Bu yüzden bu tür çalışmalara devam edilmesi gerekmektedir.

Son yıllarda söz varlığına dayalı "Derleme Sözlüğüne Katkılar" adı altında değişik yörelerdeki sözler derlenmiş ve yayımlanmıştır. Bunları burada tek tek zikretme gereği duyulmamıştır. Bu çalışma da bu alan hizmet eden bir yazıdır.

\section{Demirci ve Demirci'de Halıcılık}

Demirci Manisa'ya bağlı, 2017 nüfus sayımına göre nüfusu 41.123 olan iç Ege'de yerleşik küçük bir ilçedir. Manisa'ya 165 km uzaklıkta, doğu ve kuzeydoğusunda Kütahya, kuzeyinde Balıkesir ili, güneyinde Manisa'nın ilçelerinden Selendi ve Kula, batısında Gördes ve kısmen Köprübaşı ilçeleriyle sınır olan ilçenin kuzey ve kuzeydoğusunda Demirci-Simav dağları ve batısında Türkmen dağı yer almaktadır. Coğrafi konumundan dolayı sulu tarıma elverişli arazisi pek fazla bulunmayan ilçenin gelir kaynaklarının başında susuz tarım, hayvancilık ve halıcılık gelmektedir.

Demirci'de halıcılık son üç yüz yıl içinde faaliyet gösteren ve hem Türkiye sınırları içinde hem de dış ülkelerde şöhret kazanmış bir sektör olmuştur. Özellikle el dokumacilığında Gördes, Kula, Simav gibi ilçelerde dokunan halılarla boy ölçüşecek seviyede kaliteli halılar üretilmiştir. 13.yüzyıldan itibaren Türk boylarının yöreye yerleşmesi ve buralarda yerleşik hayata geçmesinden sonra başlıca geçim kaynağı hayvancılık olan bu boylar arasında halıcılık da yaygınlaşmıştır. Bölgedeki Türkler yöresel desenlerle, kendi ihtiyaçları için halı, kilim ve benzeri dokumalar üretmişlerdir (Manisa Valiliği 2017).

Gördes ve Kula halılarıyla benzerlikler arz eden Demirci Halıları, 19. ve 20. yüzyıl başlarında dış satıma yönelik çalışan şirket ve tüccarların batı zevkine uygun siparişleri nedeniyle kalite ve desen yönünden bozulma gösterdiyse de, günümüzde bu yozlaşmanın halıcılığa verdiği zararın anlaşılmasıyla aslına uygun, yüksek kalitede halılar dokunmaya başlamıştır (Manisa İl Kültür ve Turizm Müdürlüğü 2017). 21.000 el halısı tezgahı ile piyasanın istediği renk desen ve kalitede halı üretimi gerçekleştiren ilçede Antik, Milas, Yörük, Kars, yağcı bedir, Azeri, Nepal tipi el halıları dokunmaktadır.

\section{3. Çalışmanın Amaç ve Yöntemi}

Köklü bir dokumacılık geçmişi bulunan Demirci'de tabiatıyla bu faaliyete yönelik zengin bir söz varlığı da oluşmuştur. Bu çalışmada, bu söz varlığı üzerinden Derleme Sözlüğ̈̈'ne katkıda bulunmayı amaçladık. Bunun için öncelikle ilgili söz varlığına dair bölgeden bir derleme yaptık. Ardından bu sözleri Derleme Sözlüğ̈̈'nü tarayarak bir karşılaştırmaya tabi tuttuk. Derleme Sözlüğü̈'nde bulunmayanları, sözlükte bulunuyor olsa da "Demirci" yöresine değinilmemiş olanları ya da yörede farklı anlamlarda kullanılanları belirledik. Makalenin kapsamı, bu sözlerin incelenmesi ile sınırlandırılmıştır. 


\section{Demirci'de Kullanılan Halıcılık Terimleri}

Bu çalışmanın konusunu oluşturan terimler, el dokumacılığına dayanmaktadır. El dokumacılığında kullanılan terimlerden tespit ettiklerimizi değerlendirip Derleme Sözlü̆g̈̈'nde bunların yer alıp almadığını belirledik. Tespit ettiğimiz terimleri genel olarak iki grupta inceledik: Derleme Sözlüğ̈̈'nde bulunup, sözcügün derlendiği bölgeler arasında Demirci'ye yer verilmemiş olanlar ve Demirci'de kullanılıp Derleme Sözlü̈̆̈̈'nde yer almayan terimler. Açıklama ihtiyacı duyulan yerlerde, bu sözcüklerin altında yorumlarda bulunulmuştur.

Tespit ettiğimiz bu sözler şunlardır:

alt tahtasl, ara urganı, argeç, atgl, çakl, çeki, çezgi, e'lik (eklik), eriş, gıyı örneği, güzü ağeci, halı tezgâhı, iç (orta) örneği, ilme, kirkit, makas, örnek, sandık, sıyırdım, su, ters ilme, yanlık, yumak.

\subsection{Derleme Sözlüğ̈̈''nde bulunup Demirci'ye yer verilmemiş olanlar:}

atg1 (II) [atgu, atkı (II), atma (I)] Dokumacılıkta, halıc1lıkta çözgüler arasına gelen ip (Aydoğmuş Keçiborlu -Isp.; Iğdır, Çiril - Dz.; -Ky.) (DS I: 368).

Bu terim Demirci ağzında atg̊ şekliyle kullanılmaktadır.

$\mathrm{Bu}$ gruptaki sözlerin büyük çoğunluğunda derleme yeri olarak Manisa ve çevre ilçeleri gösterilmiş, ancak bu bölgeler arasında Demirci'ye yer verilmemiştir. Bu sözler şöyle siralanmaktadır:

argaç (I) 1. Dokumalarda çözgü üzerine enliliğine atılan ip (Akhisar, Gördes - Mn.) (DS I: 308).

argeç (I) (Karamanlı Tefenni - Brd.: Karahisar, Yukarıboğaz Tavas - Dz.: - Ba.: Yenice Emet - Kü.: Bodrum - Mğ.)

Demirci ağzında 'argeç' olarak söylenir.

çeki (II) Halıyı tezgaha çekme (Gördes - Mn.) (DS III: 1112).

Demirci'de "halıyı tezgâha çekme işinde kullanılan, önceleri ağaçtan olan alet" anlamındadır. Sözlükte Demirci'ye ve bu anlamına yer verilmemiştir.

çözgü 1. Dokunacak bezin uzunluğunu meydana getiren iplik (-Mn.). 2. Dokumada önce hazırlanan ve tezgâha takılan iplik. 3. Dokumacıların yumak yapmak için kullandığı bir araç (DS III: 1300).

çezgi [çezği] Halı dokuma tezgâhlarına gerilen sıra ipler (-Brd.; -Kü.; Bozan - Es.: Arapkir - Ml; Bor -Nğ.), [çez̆̆i] : (Savaştepe - Ba.; Hisarcık - Ky.) (DS III: 1156).

Demirci' de çezgi şeklinde kullanılmaktadır.

eriş (I) 1. Dokuma tezgahlarında uzunluğuna atılan ip, arış, boy ipliği. 7. Halının geçki ipi (Gördes - Mn.: -Sn.) (DS V: 171); eriş Dokuma ipliği (Kula - Mn.) (DS XII: 4497).

Yedinci anlamıla Demirci'de de kullanılmakla birlikte, burada Demirci'ye yer verilmemiştir.

güzü Dokuma aygıtında iplikleri çaprazlama işinde kullanılan ağaç (Gördes - Mn.; Yeniköy - Ba.) (DS VI: 2244).

Demirci ağzında "güzü ağacı/ağeci" olarak bu anlamda kullanılır.

ilme I. [ilmah] 1. Halı ya da dokuma dokunurken atılan düğüm, ilmek (Mn. ve çevresi). 2. Halıya düğümlenen renkli iplerin her biri (Bünyan -Ky.; Kaya Fethiye, Pinarlibelen Bodrum -Mğ.) (DS VII: 2531).

kirkit (I) Dokumacılıkta atkı ipliğini sıkıştırmak için kullanılan, demirden ya da ağaçtan yapılmış dişli araç (Gördes, Kula - Mn.) (DS VIII: 2879).

sıyırdım (II) 1. Halının genişliğine atılan ilmek sırası (Gördes - Mn.) 2. Halıda atkı ipi (-Ba.) (DS X: 3624). 
su (I) 1. Halı, perde, örtü vb. eşyaların dört kıyısına konulan çizgiler ya da çiçek biçiminde süsler (Gördes-Mn.; Bor, Koyunlu -Nğ.; Ermenek - Kn.) (DS X: 3686).

\subsection{Derleme Sözlüğ̈̈̈'nde yer almayıp Demirci'de kullanılan terimler:}

Bu terimler tarafımızdan anlamlandırılmıştır.

alt tahtası Halı dokuma esnasında dokuyanların oturduğu tahta.

DS'nde buna benzer olarak "alt ağacı/alt mazısı" maddesi bulunmaktadır; ancak "dokuma tezgâhında dokunan halı veya kilimin sarıldığı yuvarlak ağaç" (DS I: 229) anlamiyla yer almaktadır.

ara urganı Halı çözgüsünü önden ve tersten sıkılaştırmaya yarayan urgan.

e'lik / eklik Halının su kısmında bulunan bir bölüm. örnek.

gıyı örneği Halının su kısmında dokunacak motifi gösteren, mukavva üzerine çizilmiş

iç (orta) örneği Halının asıl desenini oluşturan bölümü gösteren, mukavva üzerine çizilmiş örnek.

ters ilme Ters atılan bir ilme türü.

Tespit ettiğimiz terimlerden bazıları, standart dilde kullanım alanına sahip olan sözlerdir. Bu nedenle Derleme Sözlü̆̆̈̈'nde yer almamaları doğal karşılanabilir. Bunlardan bazıları aşağıda verilmiştir:

çakı Atılan ilmeği kesen bıçak.

Derleme Sözlüğ̈̈'ndeki çakı (I), (II), (III) (DS II: 1042), bu terimden farklı maddeleri ifade etmektedir.

halı tezgâhı Halı dokumaya yarayan tezgâh. Demirci'de ağaç ve demir tezgâh olmak üzere iki tür halı tezgâhı kullanılır.

makas Halı ilmeklerini aynı boyutlara getirmek için ilmekleri kesmede kullanılan alet. örnek Dokunacak halının deseni ve desenin çizildiği mukavva.

sandık Alt tahtasının altında her iki yanına ve ortasına yerleştirilen destek.

Derleme Sözlü̈̆̈̈'nde sandik III maddesinde "halıcllıta kıyı suyu ile orta süsü arasındaki bölüm (Bor-Niğ.)" anlamıla verilen bu terimle anlamca uzak kalmaktadır (DS X: 3536).

yumak Yuvarlak biçimde sarılmış yün.

\section{SONUÇ}

Yaptığımız bu araştırma sonucunda Demirci bölgesinde kullanılan halıcılık terimlerinin derlenmediğini ve bu yüzden Derleme Sözlüğü'ne alınmadığını görmüş olduk. Hem Derleme Sözlüğ̈̈'ne hem ağız çalışmalarına katkıda bulunmak amacıyla yapmış olduğumuz bu çalışmayla, Demirci'de kullanılan halıcılık terimlerini kısmen de olsa belirlemiş olduk.

Çalışmamızın sonunda; Derleme Sözlüğ̈̈'nde "argaçlargeç, eriş, çeki, kirkit, çözgü/ç̧ezgi, styırdım, su, ilme ve güzü" terimlerinin tespit edildiği yerler arasında Manisa ve bazı ilçelerinin verilmesine rağmen Demirci'nin zikredilmediğini gördük. Yine Manisa ve yöresinde hiç tespit edilmemiş terimlerin olduğunu da gözlemledik. Örneğin: atgı (II). Bazı terimler de Derleme Sözlüğü'nde hiç yer almamakla birlikte Demirci bölgesinde halıcılık terimi olarak kullanılmaktadır. Bu sözler şunlardır: alt tahtası, ara urganı, e'likleklik, ters ilme, gıyı örneği, iç (orta) örneği. Ayrıca bazı terimlerin Derleme Sözlüğ̈̈'nde verildiği anlamlardan farklı anlamlarda Demirci bölgesinde kullanıldığını da belirledik: alt tahtası, çakı, örnek, sandık gibi. 
Demirci ilçesi halıcılık terimleri özelinde yapmış olduğumuz bu incelemeden yola çıkarak; ağızların söz varlığının ortaya konmasında, genel derlemelerin yanı sıra, bu şekilde belirli alanlara yönelik çalışmaların da önem taşıdığını söylemek mümkündür.

\section{SUMMARY}

In this study, some terms used in Demirci carpet weaving are analysed and it is explored whether these words exist in Derleme Sözlüğ̈̈̈, a 12-volume publication of Turkish Language Association. Demirci is a district of Manisa in Aegean region. In the district, carpet weaving has a long history and it is an important source of income of the area. Demirci carpets have an international reputation. In recent years, this situation is deteriorated with the development in the carpet industry and the number of carpet weavers has decreased. For this reason, it is necessary to identify these region-specific terms as soon as possible and include them in the Derleme Sözlüğ̈̈. In this study, some carpet weaving terms that are used in Demirci are analysed in comparison with the Derleme Sözlüğü. The aim of the study is to reveal the vocabulary that arose from carpet weaving in the area. Thus, it is also attempted to contribute to Turkish dialectology studies which is an important research area in Turkey. The studies about the Anatolian dialects are many. The most important work in this field is the compilation activity which was conducted all over the country by Turkish Language Association in 1930s. After finishing all compilations which were done in different periods, 12-volume "Türkiye'de Halk A ğzindan Derleme Sözlüğ̈̈" was published. The dictionary, based on more than 600.000 index cards, is the most comprehensive work in this field. Of course new works are going on to reveal the full vocabulary of Turkish dialects. New studies related to various dialect regions are trying to eliminate the deficiencies and to contribute to Derleme Sözlüğ̈̈ in the light of modern methods. We also carried out our study based on Derleme Sözlüğ̈̈. In the collection of the data, firstly we compiled material from the area. We referred to weavers as a source. Then, we compared this material with Derleme Sözlüğü. Based on this comparison, we determined the words that are not found in the dictionary, words in the dictionary which are not referred to Demirci or have different meanings in Demirci from the dictionary. The scope of the study is limited to the examination of these words. The words we determined are: alt tahtası, ara urganl, argeç, atgl, çakl, çeki, çezgi, e'lik (eklik), eriş, gıyı örneği, güzü ă̆eci, halı tezgâhı, iç (orta) örneği, ilme, kirkit, makas, örnek, sandık, sıyırdım, su, ters ilme, yanlık, yumak. Among these, atgı (II), argaç (I), çeki (II), çözgü, eriş, güzü, ilme (I), kirkit (I), sıyırdım (II), sù (I) are not referred to Demirci in the dictionary. And those words we compiled from Demirci that are not found in the dictionary are: alt tahtasl, ara urganl, e'likleklik, gıyı örneği, iç (orta) örneği, ters ilme, çakı, halı tezgâhı, makas, örnek, sandık, yumak. 


\section{KAYNAKÇA}

Akkuzu, Zehra. Kaynak Şahıs. Yaş: 53. Demirci Merkez.

Akyol, Senem (2006). Manisa Merkez Kuzey-Batı Köylerinin Ağız Özellikleri. Yüksek Lisans Tezi. Manisa: Celal Bayar Ü.

Buran, Ahmet - İlhan, Nadir (2008). Elazığ Yöresi Söz Varlığı. Ankara: TDK Yay.

Caferoğlu, Ahmet (1994). Anadolu Diyalektolojisi Üzerine Malzeme I-II. Ankara: TDK Yay.

Caferoğlu, Ahmet. Anadolu Ağızlarından Toplamalar. Ankara: TDK Yay.

İlker, Ayşe (2017). Manisa Ağızları. Ankara: TDK Yay.

Karahan, Leyla (1996). Anadolu Ağızlarının Sinıflandırılması. Ankara: TDK Yay.

Korkmaz, Zeynep (1994). Güney-Batı Anadolu Ağıları Sesbilgisi(Fonetik). Ankara: TDK Yay.

Oyar, Ahmet (1998). Salihli İlçesi ve Köyleri Ağızlarından Derlemeler. Yüksek Lisans Tezi. Edirne: Trakya Ü.

Ölmez, Mehmet (2010). "Anadolu Ağızları Sözlüğü'ne Ekler Projesi ve 2006'daki Durumu". I. Uluslararası Türk Diyalektolojisi Çalıştayı, 15-20 Mayıs 2008. Gazi Magosa/Kıbrıs. Türk Dilleri Araştırmaları (20): 187-192.

Özdurak, Hikmet. Kaynak Şahıs. Yaş: 80. Demirci Merkez.

T.C. Kültür ve Turizm Bakanlığı Manisa İl Kültür ve Turizm Müdürlüğü. “Kültür/Somut Olmayan Kültürel Miras/Yöresel Değerlerimiz/Demirci Halıları http://www.manisakulturturizm.gov.tr/TR,151968/demirci-halilari.html [2017.09.11]

T.C. Manisa Valiliği. “İlçelerimiz/Manisa/Demirci/Sanat El sanatları Halı Dokuma". http://manisafx.mekan360.com/iys ilcelerimiz, sehirID=45, ilceID=602,icerik=9 1,sayfa=1-ilcelerimiz-el-sanatlari-hali-dokuma.html?\#detay [2017.09.11].

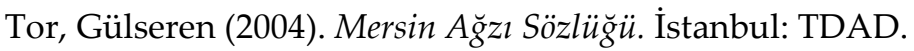

Türk Dil Kurumu (1993). Türkiye'de Halk Ağzindan Derleme Sözlüğü (12 Cilt). Ankara: TDK Yay. 